\title{
Erratum zu: Die inklusive Schule
}

\author{
Kooperation mit Schulbegleitungen als schulexterner Akteursgruppe
}

\section{Erratum zu:}

\section{Sozial Extra 2020}

https://doi.org/10.1007/s12054-020-00302-6

Der Artikel „Die inklusive Schule“ von Albrecht Rohrmann und Hanna Weinbach wurde ursprünglich Online First ohne „Open Access“ auf der Internetplattform des Verlags publiziert. Nach der Veröffentlichung in Band 44 Heft 4 pp. 194-197 hatten sich die Autoren für eine „Open Access“-Veröffentlichung entschieden. Das Urheberrecht des Artikels wurde deshalb in (C) Der/die Autor(en) 2020 geändert. Dieser Artikel ist jetzt unter der Creative Commons 4.0 International Lizenz veröffentlicht, welche die Nutzung, Vervielfältigung, Bearbeitung, Verbreitung und Wiedergabe in jeglichem Medium und Format erlaubt, sofern Sie den/die ursprünglichen Autor(en) und die Quelle ordnungsgemäß nennen, einen Link zur Creative Commons Lizenz beifügen und angeben, ob Änderungen vorgenommen wurden.

Die in diesem Artikel enthaltenen Bilder und sonstiges Drittmaterial unterliegen ebenfalls der genannten Creative Commons Lizenz, sofern sich aus der Abbildungslegende nichts anderes ergibt. Sofern das betreffende Material nicht unter der genannten Creative Commons Lizenz steht und die betreffende Handlung nicht nach gesetzlichen Vorschriften erlaubt ist, ist für die oben aufgeführten Weiterverwendungen des Materials die Einwilligung des jeweiligen Rechteinhabers einzuholen.

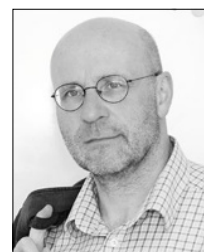

Albrecht Rohrmann

Siegen, Deutschland

*1962; Professor für Sozialpädagogik mit dem Schwerpunkt soziale Rehabilitation und Inklusion im Department Erziehungswissenschaften und Psychologie der Universität Siegen. rohrmann@zpe.uni-siegen.de

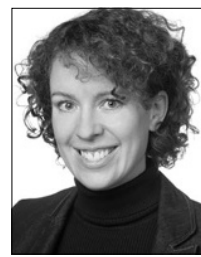

Hanna Weinbach

Siegen, Deutschland

*1980; Dr. phil., Diplom-Pädagogin, Diplom-Sozialpädagogin, Akademische Rätin im Department Erziehungswissenschaften und Psychologie der Universität Siegen.

hanna.weinbach@uni-siegen.de
Weitere Details zur Lizenz entnehmen Sie bitte der Lizenzinformation auf http://creativecommons.org/licenses/by/4.0/deed.de.

Die Online-Version des Originalartikels ist unter https:// doi.org/10.1007/s12054-020-00302-6 zu finden.

Funding. Open Access funding enabled and organized by Projekt DEAL.

Open Access. Dieser Artikel wird unter der Creative Commons Namensnennung 4.0 International Lizenz veröffentlicht, welche die Nutzung, Vervielfältigung, Bearbeitung, Verbreitung und Wiedergabe in jeglichem Medium und Format erlaubt, sofern Sie den/die ursprünglichen Autor(en) und die Quelle ordnungsgemäß nennen, einen Link zur Creative Commons Lizenz beifügen und angeben, ob Änderungen vorgenommen wurden.

Die in diesem Artikel enthaltenen Bilder und sonstiges Drittmaterial unterliegen ebenfalls der genannten Creative Commons Lizenz, sofern sich aus der Abbildungslegende nichts anderes ergibt. Sofern das betreffende Material nicht unter der genannten Creative Commons Lizenz steht und die betreffende Handlung nicht nach gesetzlichen Vorschriften erlaubt ist, ist für die oben aufgeführten Weiterverwendungen des Materials die Einwilligung des jeweiligen Rechteinhabers einzuholen.

Weitere Details zur Lizenz entnehmen Sie bitte der Lizenzinformation auf http://creativecommons.org/licenses/by/4.0/deed.de. 